\title{
Text cohesion and metacomprehension: Immediate and delayed judgments
}

\author{
N. LEFÈVRE and G. LORIES \\ Université catholique de Louvain, Louvain-la-Neuve, Belgium
}

\begin{abstract}
In three experiments, we examined comprehension judgments made after a piece of text had been read. We propose that such metacognitive judgments are based on the content of working memory at the exact moment of assessment. Generally speaking, this working metacognition hypothesis is in agreement with Koriat's cue utilization approach, which implies that different elements of information will be available (and used) depending on the moment at which a judgment is made. More specifically, our hypothesis focuses on the management of working memory during reading as a cause for cue (un)availability. In support of these views, the results of Experiment 1 showed that a cohesion manipulation affecting the comprehension of specific paragraphs influences judgments only on these paragraphs, and not on judgments on the whole text. In Experiment 2, we showed that an interfering task that takes place just before this paragraph judgment is made wipes out this cohesion effect. Experiment 3 showed, on the other hand, that the whole-text judgment may, nevertheless, be affected by text cohesion, provided that the readers keep an access to the text when the judgment is made. These results support the idea that working memory management makes different cues available for metacognitive ratings at different delays.
\end{abstract}

Over the last 20 years, research into the self-assessment of text comprehension and memorization has grown rapidly (Pratt, Luszcz, MacKenzie-Keating, \& Manning, 1982; Shaughnessy, 1979; Wearn \& Askwall, 1981). The problem is of practical interest - for instance, in education (Garner, 1987; Hacker, Dunlosky, \& Graesser, 1998; Wray, 1994) — and several studies have clearly expressed a preoccupation with practical applications (Cross \& Paris, 1988; A. King, 1991; Palincsar \& Brown, 1984; Zechmeister, Rusch, \& Markell, 1986). From an educational point of view, the research objective is to improve children's performance by improving their metacognitive abilities. For instance, according to Paris and Winograd (1990; see also Hacker, 1998), students can enhance their learning by becoming aware of their own thinking as they read, write, and solve problems.

This approach requires that metacognition be actually adaptive. In text comprehension, for instance, metacognition should actually support better integration of propositions and better text comprehension (Moore, Zabrucky, \& Commander, 1997). This, in turn, implies that metacognition must be reasonably accurate and must be sensitive

Part of this work was supported by a grant from the Belgian federal government (IUAP 4/19 on "Temporal Control of Dynamic Task Situations and the Nature of Human Knowledge Representation") and by an FNRS grant "Crédit aux chercheurs" to G.L. The authors thank J. Dunlosky, R. H. Maki, and an anonymous reviewer for insightful comments on earlier versions of this article. Correspondence concerning this article should be addressed to N. Lèfevre, Université catholique de Louvain, Department of Psychology, 10, Place du Cardinal Mercier, B 1348 Louvain-la-Neuve, Belgium (e-mail: nathalie.lefevre@psp.ucl.ac.be). to most of the factors that affect comprehension. Since explicit metacognitive judgments are the most obvious form of assessment of metacognition, appropriate metacognitive abilities should yield accurate metacognitive judgments. Some results support this view regarding memory efficiency (Hertzog, Dixon, \& Hultsch, 1990) and the effects of specific characteristics of the study situation on memory efficiency (e.g., retrieval practice; J. F. King, Zechmeister, \& Shaughnessy, 1980).

Comprehension and metacomprehension could also be expected to vary together as a function of such factors as the number of times a text is read (Ehrlich \& Cahour, 1991; Rawson, Dunlosky, \& Thiede, 2000) or the material presentation modality (Carroll \& Korukina, 1999), but the results have not always been consistent: Cognition and metacognition do not always covary. For instance, some studies do support the idea that metacognitive judgments are sensitive to cohesion manipulations, but some do not. Britton, Gülgöz, Van Dusen, Glynn, and Sharp (1991) showed an effect of text legibility on a metacognitive judgment (a learnability judgment). Their readers compared two versions of a same text and decided which of the two versions would produce the best recall performance after $24 \mathrm{~h}$. The subjects usually chose the version that had produced the best recall in a previous study (Britton \& Gülgöz, 1991; Britton \& Radford, 1988; Britton, Van Dusen, Gülgöz, \& Glynn, 1989). Ehrlich and Cahour also found an effect of cohesion (presence vs. absence of connectives, simple or complex anaphora) on comprehension judgments, but only after a second reading. Yet a recent study by Degand, Lefèvre, and Bestgen (1999), in which manipulations similar to Ehrlich and Cahour's were used, 
showed no effect of manipulating linguistic cohesion on the comprehension judgment, even though comprehension itself was affected.

There may be a way out of this difficulty. The results of Ehrlich and Cahour (1991) and of Degand et al. (1999) were obtained for judgments emitted at different moments. In Degand et al., the judgment was made after the whole text had been read (a procedure that we will call delayed from now on), whereas in Ehrlich and Cahour, metacognitive judgments were emitted immediately after the presentation of each text segment (a procedure that we will call immediate from now on). The comprehension judgment used by Degand et al. was also different from the learnability judgment in Britton et al. (1991), because in Britton's experiment, the readers could always go back to the most difficult parts and/or compare versions when making their judgments. In other words, the circumstances in which each of these judgments was emitted were different.

One possible interpretation of these diverging results rests on the fact that metacognitive ratings given while the text remains present (Britton et al., 1991) or during reading (Ehrlich \& Cahour, 1991) are affected by reading difficulties but ratings given after the whole text has been read remain unaffected (Degand et al., 1999). This suggests that the particular result in Degand et al. may have occurred because different cues were used for each type of judgment, according to the moment the judgment was made. The object of the present research was to reproduce and explore this type of dissociation.

This research direction seems a fruitful one because the idea of a judgment based on different cues, according to the context in which it is made, has already met with some success in the metacognition literature. For instance, Koriat (1997) suggested that metacognitive judgments are based on various inferences and heuristics. According to this cue utilization framework, the judgment of learning (JOL) or the feeling-of-knowing (FOK) judgment, as well as many other metacognitive judgments, probably would rest on a variety of cues that are only globally predictive of performance. The relative weight of different cues when a judgment is made may differ from one experimental condition to another and may also change with practice.

In the case of comprehension, one important set of cues is provided by working memory (WM) content, but this content keeps changing during reading. Text comprehension requires a continuous encoding of new propositions that must be processed and integrated with previously processed information. WM carries out both the storage and the processing of these propositions: Because WM capacity is limited, many elements must be removed or restored as processing goes on, in order to allow for the entrance of the required elements. Therefore, many elements that are available at some point during reading are bound to be unavailable at another, and some of them can be cues used for metacognition.
This suggests a difference between the cues that are available during the reading of a specific piece of text and those available after the reading of all of the text. Immediate comprehension judgments will reflect difficulties encountered during reading, because some traces of these difficulties remain available in WM. Because this information remains available in WM, immediate judgment can rely on the existence of not-yet-integrated elements or can take into account the memory of difficulties that have been solved only very recently.

WM cues certainly relate to on-line functioning, but the delayed comprehension judgment is the final one. So it probably bears on the representation as it is finally constructed, not on the representations built at intermediate stages, when elements of information may be missing simply because reading is not over yet. The reason is that the reader is normally supposed to read and, possibly, reread a text until comprehension is achieved; concretely, this means until a coherent enough representation of the content of the text has been built. Inferences will have to be made until a high enough standard of cohesion is reached (van de Velde, 1989; see also van den Broek, Risden, \& Husebye-Hartmann, 1995). It would therefore be globally appropriate for a delayed metacognitive judgment to tap only the quality of the final, integrated representation and to be insensitive to problems that occurred during reading (Otero \& Kintsch, 1992). This suggests that it will rest on different cues, available at a different moment.

In summary, because of the central role of WM in comprehension, we make the hypothesis that metacognitive judgments are based on WM cues and that changes in cues are due to WM management as reading progresses. We call this specification of Koriat's approach the working metacognition (WMC) hypothesis. This hypothesis can explain some of the problems having to do with metacognitive judgments. If the content of WM is used to assess comprehension, the judgment will change with the content of WM. In particular, it will be different during and after reading: Immediate judgments will reflect difficulties encountered during reading that temporarily leave traces in WM; delayed judgments will be based on whatever remains available after reading.

Because the WMC model rests on the (un)availability of specific items of information in WM, it is similar to Morris's momentary accessibility hypothesis (Morris, 1990). Both conceptions are, nevertheless, distinct. In Morris's experiments, the relevant cue was trace accessibility itself, assessed at the time at which the judgment was made. As we understand this, it implies an ease-ofaccess judgment based on access latency or instantaneous retrieval rate. For instance, the activation of memory content may decay, and as a result, ease of access may change, yielding a different metacognitive judgment. In our interpretation of what happens during reading, the set of available relevant cues changes, not just the accessibility of any of them. 
Our analysis is, therefore, closer in spirit to the monitoring dual memories hypothesis (Nelson \& Dunlosky, 1991) regarding the JOL. Nelson and Dunlosky discuss a learning judgment emitted when paired associates are learned. The participants were given a cued recall task. Between learning and recall, they had to predict their recall performance for each recall cue. The interesting result was that JOL accuracy, measured by a gamma correlation between judgment and performance, increased if a delay was introduced between learning and judgment (Dunlosky \& Nelson, 1992, 1994, 1997; see also Kelemen $\&$ Weaver, 1997; Weaver \& Kelemen, 1997). According to Nelson and Dunlosky's interpretation of the effect, shortterm memory information contaminates the immediate, but not the delayed, JOL. This analysis is close in spirit to our WMC proposition, because both models suggest that different elements of information will be used according to the moment at which the judgment is made. The main difference is that in the JOL context, short-term retention can play a contamination role only because the memory test (paired association) is long term. With regard to the comprehension judgment, the problem is slightly different. Temporary cues may or may not be valid, depending on circumstances. Forgetting these cues is actually appropriate if a correct interpretation of the text has been constructed, but the interpretation of the text may be erroneous, and so the consequences for accuracy are more difficult to predict than in the JOL case.

Various specific predictions can be made on the basis of the WMC model. The delayed judgment should remain unaffected by difficulties encountered during reading, provided that these difficulties have been solved. Such difficulties should have no effect on a delayed judgment if a coherent representation has eventually been constructed. Experiment 1 tested this prediction. It should be noted, though, that the representation constructed to solve the inference problems may be correct or not. In other words, delayed judgments should be insensitive to problems that have been solved in some way. The representation constructed during reading may be satisfying to the reader but wrong (for examples, see Lefèvre, 2003; Otero \& Kintsch, 1992).

Now suppose that we compare a high-cohesion (HC) and a low-cohesion (LC) version of a same text. Another prediction of the WMC model is that immediate judgments should not be affected by text cohesion if something prevents the reader from keeping the relevant elements of information in WM. An interfering task between the reading of a paragraph and the judgment regarding this paragraph will have this effect. It will occupy WM, so that WM information about the cohesion difficulties will be lost and should, therefore, wipe out the cohesion effect because it delays the judgment, so to speak. Experiment 2 tested this prediction.

A final prediction of the WMC model is that even delayed judgments may be affected by text cohesion if the readers are allowed to return to the text when they give their rating. Reintroducing the text elements related to a cohesion difficulty should make the judgment sensitive to it. Experiment 3 tested this prediction.

We wanted Experiment 1 to show that delayed judgments are sensitive to at least some manipulations. The manipulation used to that purpose was to have an effect on comprehension and had to be crossed with the manipulation generating the transient difficulties. We chose to force the subjects to read more rapidly than usual in the experimental condition. Reducing the available time was expected to lower comprehension and to provide a nontransient mnemonic cue, because such a reading should lead to a poorer representation of the content, containing more important (unsolved) inferential gaps. The task should prevent the reader from correctly integrating some of the new propositions to the existing representation. If the reader has insufficient time to achieve a complete integration, some reading difficulties cannot be solved at all, and the resulting representation will be poorer. Moreover, forcing the subjects to read rapidly also provides an extrinsic cue (Koriat, 1997) that can, by itself, lower the metacognitive judgments, because the reader knows that time pressure should reduce performance. So the manipulation should affect both types of metacognitive judgments and provide a guarantee that the delayed judgment has at least some sensitivity.

Although it was designed as a validity check, this manipulation also happens to have a theoretical interest of its own. Interestingly, some results in the literature do not fit well with our hypothesis that comprehension should deteriorate when cohesion decreases. Breznitz and Share (1992) reported a comprehension gain, instead of a performance decrease, in accelerated reading in a sequential self-presentation paradigm. We would expect accelerated reading to be similar to a lower cohesion condition, due to the lack of processing time. The manipulation provides empirical elements on this point. It is also of interest to observe the detailed effect of such an accelerated condition on the reading of paragraphs involving local comprehension difficulties. The procedure allows us to determine whether the negative effect of the reduced reading time is more important in the manipulated parts of the text.

Finally, there may be an interaction between the cohesion and the pace-of-reading manipulations on metacomprehension judgments. Although the WMC model makes no specific prediction on this point, observing such an interaction would suggest that metacomprehension judgments can be influenced simultaneously and nonadditively by different cues. Using two different manipulations simultaneously provides some information on the relative weight given to the cues at different moments and in specific combinations. Ultimately, this may help us understand how students concretely make metacognitive judgments.

At this point, our predictions can be compared with those implied by a number of other theoretical conceptions. Our predictions do not fit with a general adaptation hypothesis, because it would imply that comprehen- 
sion effects should always be reflected in metacognitive judgments. The WMC hypothesis predicts no cohesion effect on delayed judgment.

Our predictions do not fit either with the cue utilization hypothesis (Koriat, 1997). The cue utilization hypothesis is usually, and perhaps somewhat arbitrarily, taken to imply that judgments are more sensitive to intrinsic factors than they are to extrinsic factors, which tend to be discounted for remembering tasks. This smaller effect of extrinsic factors on judgments would be especially apparent in a between-subjects design (Carroll \& Nelson, 1993). In the case of comprehension, this suggests that a judgment will be affected more by cohesion cues (intrinsic cues) than by pacing (extrinsic cues) manipulated between participants. The WMC hypothesis predicts exactly the reverse pattern: For delayed judgments, the larger, or the only, effect should stem from the pace-ofreading manipulation. Although we predicted an effect of both types of cues on the immediate judgment, we predicted only a pacing effect, and not a cohesion effect, on the delayed judgment.

In the three experiments to follow, comprehension judgments were asked both immediately (after a paragraph had been read) and after a delay (after the whole text had been read). In Experiment 1, we manipulated cohesion by making anaphora more or less difficult and the overall integration by imposing a time constraint. In Experiment 2, the same procedure was used, but an attempt was made to specifically clear WM, in order to demonstrate the role of WM content in making judgments. Experiment 3 left the text accessible, to reinstall difficulties in WM, and showed that delayed judgments can also be sensitive to cohesion under suitable conditions.

\section{EXPERIMENT 1}

Experiment 1 was conducted to test the effect of text cohesion and time constraints on the comprehension and metacomprehension of expository text. Both the cohesion manipulation (Degand et al., 1999) and the time constraint are supposed to have an effect on comprehension performance. One also would like to know whether a more important negative effect of the time constraint can be obtained on the less cohesive parts of the text.

The experiment allowed the testing of specific predictions based on our WMC model. Concerning accuracy, we expected to observe a positive correlation between delayed comprehension judgments and general comprehension performance, because the delayed judgments, just like comprehension, would at least in part rest on features of the final representation (richness, accessibility, etc.). The same predictions can be formulated for immediate judgments, because they rest on cues (e.g., cohesion cues) that themselves affect comprehension.

As regards the cohesion effect on rating levels, we expected to observe a lower immediate judgment for LC paragraphs, because LC leads to more comprehension difficulties that temporarily leave traces in WM. At the same time, we expected to observe no effect of cohesion on delayed judgments, because difficulties would have been solved by the time the judgment was emitted.

Concerning the effect of time constraints on rating levels, we expected time constraints to have an effect on immediate judgments, because information regarding transient difficulties was available at the time the judgment was made. The same was expected for delayed judgments, because, although information regarding transient difficulties was no longer available at the time the judgment was made, the difficulties would not have been solved (would not be transient) and the final representation would be impoverished.

Finally, we tested the interaction between cohesion and time constraints on immediate judgments, to determine whether immediate judgments on manipulated paragraphs are affected differently by the time constraint as a function of the cohesion level.

\section{Method}

Pretest. Twenty native speakers of French read each text in a self-paced mode, in order to provide a mean reading time for each segment.

Subjects. Fifty-six second-year college students first read two practice texts and then six experimental texts: Three texts were read in each of the two cohesion versions. The subjects were randomly assigned to the two reading conditions: self-paced or constrained.

Materials. The experimental materials consisted of six expository texts of approximately 550 words each. All the texts were based on encyclopedic articles or scientific vulgarization and covered topics such as the Aztecs, optic fiber, concrete, the Baptists, the liver fluke, and lightning. Each had four paragraphs and existed in two versions: an HC version (control condition) and an LC one (experimental condition). Two of the four paragraphs of each text were modified to implement the cohesion effect. In each paragraph, we manipulated about eight nominal entities that referred to a previously mentioned antecedent. In the $\mathrm{HC}$ version, the anaphoric link remained unambiguous (the referential expression used was a repetition of the antecedent). In the LC version, we used an anaphora that was difficult to resolve (it was too far from the antecedent or was ambiguous in the context). Both versions of one of the texts are included in the Appendix as an example.

Eight questions were prepared for each text. Two of them specifically tapped the cohesion manipulation. The other six questions covered nonmanipulated parts (detail and integration questions). The eight questions for one of the texts are reproduced in the Appendix as an example.

Design. Two counterbalanced sets of texts were constructed. Each set contained the same six texts in one of the two versions: three texts were in the $\mathrm{HC}$ version and three in the $\mathrm{LC}$ version. Across the two sets, each text appeared once in each experimental condition. The order of the texts was random. Half of the subjects saw the texts in one random order, and half saw them in the reverse order.

Procedure. The subjects were tested individually. They were asked to read the series of texts and were warned that they would be asked comprehension and metacomprehension questions. The subjects first read two practice texts and then the six experimental texts. The whole session took $70 \mathrm{~min}$.

The texts were presented on a computer screen, segment by segment, using software developed by Gaonac'h and Passerault (see Gaonac'h \& Passerault, 1990; Passerault \& Gaonac'h, 1991) that implements a variation of the moving window technique (Just, Car- 
penter, \& Wooley, 1982). Half of the subjects read texts in a selfpaced mode; the other half were allowed $90 \%$ of the mean reading time of a pretest group for each text segment. The text presented was encrypted: Each character was replaced by a random letter. Case and punctuation were preserved. This procedure allowed preservation of typographic cues and the physical organization of the text. The segments were uncrypted temporarily as reading progressed.

The subjects gave a comprehension rating at the end of each paragraph and after reading the whole text. The question was Dans quelle mesure pensez-vous avoir compris le paragraphe (le texte) que vous venez de lire?/How well do you think you understood the paragraph (the text) you have just read? The subjects gave their ratings on a 0-20 scale ( 1 was labeled very poorly understood, and 20 was labeled very well understood). This is the scale used for class grades at UCL, and the students were used to the meaning of the levels. Questions about one text were asked only after another text had been read. In other words, after reading text $n$, the subjects answered questions regarding text $n-1$. This procedure was used to make the interval between reading and test as constant as possible for each text. A final text was used only as an interfering task between the last experimentally relevant text and the comprehension questions that referred to it. This guaranteed an interval large enough between learning and test to clear WM from any information directly relevant to the questions. At the same time, the interval remained reasonably short, in comparison with more classical situations, in which all questions are grouped and given after all texts haven been read (e.g., Lin, Zabrucky, \& Moore, 2002; Pierce \& Smith, 2001; Rawson \& Dunlosky, 2002; Rawson et al., 2000). We attempted to minimize the delay between reading and test and to keep it as constant as possible, subject to the constraint that shortterm memory was cleared. This was because Maki (1998a) had shown that a large delay between reading and test has a negative effect on accuracy.

The dependent variables were the comprehension ratings (immediate and delayed) and the percentages of correct responses on specific and other questions. There were eight questions for each text: two detail questions tapped nonmanipulated paragraphs (detail questions/nonmanipulated paragraph, D/NMP), two detail questions tapped manipulated paragraphs (detail questions/manipulated paragraph, D/MP), two questions of integration tapped nonmanipulated paragraphs (integration questions/nonmanipulated paragraph, I/ NMP), and two questions tapped the cohesion manipulation in the manipulated paragraphs (integration questions/manipulated paragraph, I/MP).

\section{Results}

Comprehension test. Answers to comprehension questions were scored on a 4-point scale, with 0 for a wrong answer, 4 for a perfectly correct answer, and 1,2, or 3 for a partial answer. The results are presented for each question type (detail vs. integration question in a manipulated vs. a nonmanipulated paragraph) and experimental condition in Table 1. They are discussed in terms of percentage for the largest possible score.

The percentages were compared across conditions in a within-subjects design. A $2 \times 2 \times 4$ (cohesion $\times$ pace of reading $\times$ question type) repeated measures analysis of variance (ANOVA) was run. This analysis showed a significant effect of pace of reading $[F(1,54)=4.38$, $p<.05]$. As can be seen in Table 1 , scores were higher for the self-paced reading condition than for the constrained reading condition. A significant effect of cohesion $[F(1,54)=12.01, p<.001]$ and a significant effect of question type $[F(3,162)=9.1, p<.001]$ were found,
Table 1

Percentages of Correct Responses on Specific and Other Questions That Tapped the Anaphoric Manipulation (Experiment 1)

\begin{tabular}{lccccc}
\hline & \multicolumn{2}{c}{ High Cohesion } & & \multicolumn{2}{c}{ Low Cohesion } \\
\cline { 2 - 3 } \cline { 5 - 6 } Group & $M$ & $S D$ & & $M$ & $S D$ \\
\hline Self-paced reading & & & & \\
IQ/MP & 51.25 & 24.81 & & 28.33 & 20.91 \\
IQ/NMP & 41.39 & 21.88 & & 37.50 & 16.81 \\
DQ/MP & 37.50 & 22.74 & 30.83 & 17.73 \\
DQ/NMP & 48.33 & 19.19 & & 48.33 & 19.93 \\
Constrained reading & & & & \\
IQ/MP & 37.18 & 19.11 & 20.99 & 15.21 \\
IQ/NMP & 36.70 & 15.32 & 35.74 & 18.45 \\
DQ/MP & 35.58 & 21.22 & 29.17 & 12.30 \\
DQ/NMP & 40.06 & 18.34 & 36.70 & 12.47 \\
Mean score & & & & \\
IQ/MP & 44.72 & 23.25 & 24.93 & 18.69 \\
IQ/NMP & 39.21 & 19.10 & 36.68 & 17.45 \\
DQ/MP & 36.61 & 21.87 & 30.06 & 15.34 \\
DQ/NMP & 44.49 & 19.09 & 42.93 & 17.73 \\
\hline
\end{tabular}

Note-IQ/MP, integrated questions/manipulated paragraph; IQ/NMP, integrated questions/nonmanipulated paragraph; DQ/MP, detail questions/manipulated paragraph; DQ/NMP, detail questions/nonmanipulated paragraph.

but we also observed a significant interaction between question type and cohesion $[F(3,162)=10.38, p<.001]$. The effect of the cohesion manipulation depended on whether the questions tapped a manipulated or a nonmanipulated paragraph. We compared the two cohesion versions in a paired $t$ test for each question type separately. We observed that only I/MP and D/MP questions showed a significant effect $[t(55)=5.3, p<.001$, and $t(55)=2.25$, $p<.05$, respectively]. Higher performance scores were observed on these questions for the $\mathrm{HC}$ paragraphs than for the LC paragraphs.

These analyses confirmed that the two manipulations were effective and comprehension was affected as intended. We first found an effect of pace of reading on comprehension performance and a specific effect of cohesion on the questions that tapped a manipulated paragraph. There was no significant interaction between pace of reading and cohesion $[F(1,54)=0.14$, n.s.], but there was a main effect of pace of reading whatever the level of cohesion. We did not observe a larger effect of cohesion manipulation on comprehension when reading time was shorter.

Accuracy of metacognitive ratings. Because we made our predictions with regard to the level of the ratings, we were not directly interested in the accuracy of metacognitive judgments when testing these predictions. Yet it would not be judicious to deal with changes in the level of comprehension ratings without assessing their validity. Moreover, the model suggests that a significant, although imperfect, correlation should be observed between cognition and metacognition, because the cues chosen by the subjects should be chosen for their presumed validity.

So, before considering the effect of the cohesion manipulation on the immediate and delayed ratings, we com- 
puted, for each subject, a correlation between the metacomprehension ratings and the comprehension scores, using each of the six experimental texts. The gamma correlation was used as the measure of relative metacognitive accuracy (see Nelson, 1984, 1996).

Accuracy of immediate ratings. We will first focus on the comprehension rating given just after each of the paragraphs had been read (immediate ratings). These ratings specifically bear on paragraphs, and not on the whole text. We computed, for each subject, a correlation between immediate ratings and the comprehension scores at each of the paragraphs across texts. The average gamma was .36. It was significantly nonzero $[t(54)=$ $15.23, p<.001]$ across subjects. ${ }^{1}$ This significant correlation is quite remarkable, considering the small number of questions for each paragraph (Weaver, 1990). We asked only two comprehension questions for each paragraph, because these questions were actually designed to assess the global comprehension of each text and to determine which question types were affected by the cohesion manipulation.

Accuracy of delayed ratings. The accuracy of the comprehension rating given after the whole text had been read (delayed ratings) was also calculated. The average gamma correlation between the delayed ratings and the comprehension performance across texts was 43. It was significantly nonzero $[t(53)=9.34, p<$ $.001]$. These results suggest that the immediate and the delayed ratings were meaningful: The various ratings were significant predictors of the comprehension scores throughout the texts.

In order to compare the accuracy of the immediate and the delayed ratings, we ran a repeated measures ANOVA contrasting the accuracy of the two rating types (immediate ratings vs. delayed ratings). This effect was significant $[F(1,53)=3.96, p=.05]$. The delayed ratings tended to be more accurate than the immediate ratings, but the lower accuracy of the immediate ratings may have been due to the small number of questions used with each judgment (see, e.g., Weaver, 1990). ${ }^{2}$
The correlations observed between judgments and comprehension are at least as good as those usually published (e.g., Maki, 1998a; Maki, Foley, Kajer, Thompson, \& Willert, 1990; Weaver, 1990). We now have to determine whether, as was predicted, the experimental manipulations affected both types of judgment differently.

Rating levels. We focused on the effect of pace of reading and cohesion and ran a $2 \times 2 \times 2$ repeated measures ANOVA contrasting the two pace-of-reading conditions (self-paced vs. constrained), the two cohesion conditions (LC vs. HC) and the two rating types (immediate ratings on the manipulated paragraphs vs. delayed ratings). This showed a significant effect of pace of reading $[F(1,54)=8.78, p<.01]$, higher ratings being observed for the self-paced reading condition than for the constrained reading condition. An effect of cohesion $[F(1,54)=4.36, p<.05]$ and an effect of rating type $[F(1,54)=28.15, p<.001]$ were found, but we also observed a significant interaction between rating type and cohesion $[F(1,54)=15.76, p<.001]$.

The interaction between cohesion and rating type was as predicted. In order to better understand it, we ran separate analyses for immediate and delayed ratings.

Immediate rating levels. We first focused on the comprehension rating given just after each of the manipulated paragraphs had been read. Table 2 presents the mean immediate ratings as a function of cohesion, pace of reading, and paragraph type. We ran a $2 \times 2$ (cohesion $\times$ pace of reading) repeated measures ANOVA on the immediate ratings (given on the manipulated paragraphs). The subjects gave a significantly higher rating when their reading was self-paced $[F(1,54)=8.92$, $p<.01]$. There was also a main effect of cohesion $[F(1,54)=8.87, p<.01]$, lower ratings being observed for the LC paragraphs. As was predicted, both manipulations (cohesion and pace of reading) did affect immediate comprehension ratings.

Table 2 shows a very low rating in the LC condition under a time constraint. This would seem to suggest that metacomprehension judgments are jointly influenced by

Table 2

Immediate Comprehension Ratings: Percentages (Experiment 1)

\begin{tabular}{|c|c|c|c|c|c|c|c|c|}
\hline & \multicolumn{4}{|c|}{ Manipulated Paragraphs } & \multicolumn{4}{|c|}{ Nonmanipulated Paragraphs } \\
\hline & \multicolumn{2}{|c|}{ High Cohesion } & \multicolumn{2}{|c|}{ Low Cohesion } & \multicolumn{2}{|c|}{ High Cohesion } & \multicolumn{2}{|c|}{ Low Cohesion } \\
\hline & $M$ & $S D$ & $M$ & $S D$ & $M$ & $S D$ & $M$ & $S D$ \\
\hline Self-paced reading & 70.86 & 14.46 & 69.08 & 14.13 & 72.66 & 12.93 & 73.81 & 12.04 \\
\hline Constrained reading & 62.76 & 11.23 & 57.56 & 11.47 & 65.32 & 12.25 & 64.74 & 11.75 \\
\hline
\end{tabular}

Table 3

Mean Scores at the Delayed Comprehension Ratings and the Comprehension Questions: Percentages (Experiment 1)

\begin{tabular}{|c|c|c|c|c|c|c|c|c|}
\hline & \multicolumn{4}{|c|}{ Delayed Ratings } & \multicolumn{4}{|c|}{ Comprehension Performance } \\
\hline & \multicolumn{2}{|c|}{ High Cohesion } & \multicolumn{2}{|c|}{ Low Cohesion } & \multicolumn{2}{|c|}{ High Cohesion } & \multicolumn{2}{|c|}{ Low Cohesion } \\
\hline & $M$ & $S D$ & $M$ & $S D$ & $M$ & $S D$ & $M$ & $S D$ \\
\hline Self-paced reading & 70.75 & 13.50 & 71.29 & 12.94 & 44.62 & 16.87 & 36.25 & 14.40 \\
\hline Constrained reading & 63.41 & 10.84 & 60.66 & 11.00 & 37.38 & 13.98 & 30.65 & 9.23 \\
\hline
\end{tabular}


ease of processing and by the time allowed to the readers to fix cohesion problems, but the interaction was not statistically significant. There was no interaction between pace of reading and cohesion $[F(1,54)=2.13$, n.s.], and this joint influence may simply be additive.

Delayed rating levels. We will now analyze the manipulations effects on the delayed ratings. Table 3 presents the mean delayed rating as a function of cohesion and pace of reading, as well as the mean comprehension performance. A $2 \times 2$ (cohesion $\times$ pace of reading) repeated measures ANOVA was run and showed that the pace of reading significantly affected the delayed comprehension rating $[F(1,54)=7.82, p<.01]$. As can be seen in Table 3, the subjects give a higher rating when their reading was self paced. There was no effect of the cohesion manipulation $[F(1,54)=1.64$, n.s. $]$ and no interaction between cohesion and pace of reading $[F(1,54)=$ $1.51, \mathrm{n} . \mathrm{s}$.]. As was predicted, the delayed comprehension rating was affected by the pace of reading, but not by the cohesion manipulation.

\section{Discussion}

The most important finding in Experiment 1 was the asymmetrical effect of text cohesion on the metacognitive judgments. The immediate comprehension judgment was affected more by the cohesion manipulation than the delayed comprehension judgment was. We observed a lower immediate judgment for LC paragraphs but no effect of cohesion on the delayed judgment. The absence of a cohesion effect on the delayed judgment is unlikely to have stemmed from a lack of accuracy, because the subjects showed the usual correlation between delayed comprehension judgment and comprehension performance. The absence of a delayed effect cannot have stemmed from a failure of the cohesion manipulation procedure either. The effect of the cohesion manipulation on the comprehension performance was significant, and it was at least as large as the one obtained with the time constraint.

We think that these results support the WMC hypothesis that metacognitive judgments are based on WM. Given the limitation of WM capacity, the elements available during reading keep changing during the comprehension process. So traces of transient difficulties are present in WM when the reader gives the immediate judgments but are no longer used at the end of the text. The cohesion effect on the delayed judgment is dampened because cues to the relevant difficulties become unavailable. The elements that remain available after reading are likely to belong to the final text representation and are not relevant to already solved difficulties. So the delayed judgment is not influenced by transient reading difficulties, but mainly by features of the final representation-its richness or its accessibility. Taken together, the absence of a cohesion effect on the delayed judgment and the significant relationship between delayed ratings and comprehension performance support this view.

The WMC model also predicts that factors that have direct effects on the richness and coherence of final rep- resentation should affect both immediate and delayed judgments. We tested this hypothesis by using the time constraint to decrease the quality of the final representation, and we actually observed a lower comprehension performance in the time-constrained condition-in contradiction with the results of Breznitz and Share (1992)and this pace-of-reading manipulation also had an effect on comprehension judgments. The time-constrained reading condition lowered not only the immediate, but also the delayed, judgments. The effect of this particular manipulation is not transient: The constrained reading leads to a less coherent and poorer representation, so that delayed judgment is lower because of the nontransient internal mnemonic indicators. Although it may be based on the richness or accessibility of the final representation, the pace-of-reading effect observed on the comprehension judgments may also reflect the effect of an extrinsic cue, although this has been described mainly for within-subjects designs. Generally speaking, these results also show that the delayed judgment can be sensitive to certain manipulations that affect the final product of comprehension.

The divergence between the results of Breznitz and Share (1992) and our own concerning the effect of time constraints on the quality of the final representation may stem from the way the reading times were set. We pretested the material and assigned to each segment $90 \%$ of its pretest mean. Breznitz and Share calculated presentation rate in the fast-paced reading condition according to the highest per-letter reading rate achieved in the self-paced condition. In their case, this was done separately for each subject. In other words, the time allowed was a property of the material in our case and the reading behavior in theirs. Yet we make no specific claim regarding what actually happened.

The joint manipulation of an intrinsic (cohesion) and an extrinsic (pace of reading) factor made possible an analysis of their joint effects on both performance and metacognition. We found no significant interaction between these factors, neither on performance nor on metacognitive judgments. Both cohesion and pace of reading had an effect on comprehension, but the situation was different for metacognitive judgments. The cohesion manipulation produced comprehension difficulties, probably perceived by the reader as temporary, that were accompanied by effects on immediate, but not on delayed, judgments. In contrast, the pace-of-reading manipulation produced permanent difficulties that were accompanied by effects on both immediate and delayed judgments. This dissociation can be explained by the WMC model, because it predicts that the cues used will depend on the content of WM at the moment the judgment is emitted.

Unfortunately, other explanations that do not entail a fundamental difference between immediate and delayed judgments can be imagined. One such explanation would rest on the amount of information involved in each judgment. Commander and Stanwyck (1997), for instance, have shown that judgments are better for long texts than 
for short passages. This provides a possible explanation for the difference between immediate judgments (bearing on paragraphs) and delayed judgments (bearing on the whole text). This confound cannot be eliminated by using only the data in Experiment 1.

In the next two experiments, we tested the model in a different way and compared it with this alternative interpretation. In order to make the amount-of-information explanation unlikely, we tried to show that cohesion effects could appear and disappear on both immediate (Experiment 2) and delayed (Experiment 3) judgments.

\section{EXPERIMENT 2}

This experiment was concerned primarily with immediate judgments. We wanted to show that under appropriate circumstances, immediate judgments can be insensitive to transient information (cues). We therefore studied the effect of an interfering task on immediate comprehension judgments. To make sure that immediate judgments did rest on a different, transient, information, we introduced an interfering task just before the judgment was made. If the content of WM is critical, manipulating this content should have an effect on the judgment. According to our hypotheses, loading WM with irrelevant elements should decrease the cohesion effects observed for immediate judgments, because the transient difficulties will have been cleared out of WM. If, on the other hand, the immediate judgment in Experiment 1 was more sensitive because it rested on small amounts of information, we should observe, in this experiment, an effect of a cohesion manipulation on immediate judgment, whatever the content of WM.

\section{Method}

Subjects. Sixty-eight second-year college students first read the two practice texts and then the six experimental texts: Three texts were read in each of the two cohesion versions. The subjects were randomly assigned to the two conditions: with or without mental arithmetic. The results of 2 subjects were not taken into account, because they did not complete the task.

Materials. The experimental materials consisted of the same six texts as those in Experiment 1. Each text had two versions: an HC version and an LC one.

The question types were the same as those in Experiment 1. Two of them tapped the cohesion manipulation. The other six questions covered nonmanipulated parts of texts (detail and integration questions).

Design. Two counterbalanced series of texts were constructed. Each contained the six texts: Three texts were in the HC version, and three were in the LC one. Across the two series, each text appeared once in each experimental condition. A random order of the texts was used. Half of the subjects saw the texts in one random order, and half saw them in the reverse order.

Procedure. The subjects were tested in groups of 10-12 in a computer room. They were asked to read a series of texts and were warned that they would be asked comprehension and metacomprehension questions. The texts were presented on a computer screen, segment by segment, using the software designed by Gaonac' $h$ and Passerault (1990). All the subjects read texts in a self-paced mode. The text appeared crypted, and the segments were uncrypted tem- porarily as reading progressed. After each text, the subjects were given the comprehension questions that tapped the text read last but one, as in Experiment 1. Moreover, the subjects gave their comprehension rating on a $0-20$ scale, a scale used for class grades at the university. They gave an immediate rating after each paragraph and also a delayed rating after reading the whole text. Half of the subjects gave their immediate ratings just after the end of paragraphs (no-interfering task, NIT). The other half solved three mental arithmetic problems before giving their ratings (interfering task, IT). The problems were one subtraction, one division, and one multiplication problem (e.g., $188-51 ; 192 / 4 ; 26 \times 19$ ). The whole experiment lasted between 70 and $100 \mathrm{~min}$.

The dependent variables were the comprehension ratings (immediate and delayed) and the percentages of correct responses on specific and other questions. The question types used were the same as those in Experiment 1.

\section{Results}

Comprehension test. Answers to comprehension questions were scored on a 4-point scale as in Experiment 1, and the results are discussed in terms of percentage for the highest possible score.

The percentages were compared across conditions. A $2 \times 2 \times 4$ (cohesion $\times$ interfering condition $\times$ question type) repeated measures ANOVA was computed. This analysis showed no effect of interfering condition $[F(1,64)=1.62$, n.s. $]$. We found a significant effect of cohesion $[F(1,64)=17.05, p<.001]$-scores were significantly higher for the $\mathrm{HC}$ version (see Table 4$)$ - and a significant effect of question type $[F(3,192)=13.89, p<$ $.001]$, but we also observed a significant interaction between question type and cohesion $[F(3,192)=10.18, p<$ $.001]$. We compared the two cohesion versions in a paired $t$ test for each question type. We observed that only the integration questions on manipulated paragraphs (I/MP)

Table 4

Percentages of Correct Responses on Specific and Other Questions That Tapped the Anaphoric Manipulation (Experiment 2)

\begin{tabular}{lccccc}
\hline & \multicolumn{2}{c}{ High Cohesion } & & \multicolumn{2}{c}{ Low Cohesion } \\
\cline { 2 - 3 } \cline { 5 - 6 } Group & $M$ & $S D$ & & $M$ & $S D$ \\
\hline No interfering & & & & \\
IQ/MP & 50.37 & 22.29 & & 32.88 & 19.18 \\
IQ/NMP & 45.47 & 21.55 & & 42.03 & 22.78 \\
DQ/MP & 51.59 & 22.68 & & 48.53 & 18.20 \\
DQ/NMP & 56.45 & 23.28 & 51.79 & 20.70 \\
Interfering & & & & \\
IQ/MP & 50.82 & 22.73 & 28.92 & 19.31 \\
IQ/NMP & 41.15 & 20.97 & 35.29 & 27.94 \\
DQ/MP & 41.67 & 23.02 & 42.58 & 22.57 \\
DQ/NMP & 50.30 & 23.14 & 46.87 & 26.95 \\
Mean score & & & & \\
IQ/MP & 50.59 & 22.33 & 30.91 & 19.20 \\
IQ/NMP & 43.37 & 21.22 & 38.76 & 25.44 \\
DQ/MP & 46.78 & 23.21 & 45.64 & 20.50 \\
DQ/NMP & 53.47 & 23.24 & 49.41 & 23.88 \\
\hline
\end{tabular}

Note-IQ/MP, integrated questions/manipulated paragraph; IQ/NMP, integrated questions/nonmanipulated paragraph; DQ/MP, detail questions/manipulated paragraph; DQ/NMP, detail questions/nonmanipulated paragraph. 
showed a significant effect $[t(65)=6.56, p<.001]$. As can be seen in Table 4, higher scores were observed specifically on the integration questions for the HC paragraphs than for the LC one. These analyses confirm that the cohesion manipulation was effective. The interfering manipulation did not interfere with comprehension.

Accuracy of metacognitive ratings. We again checked whether the different ratings were significant predictors of the comprehension scores throughout the texts. The gamma correlation was used as a measure of the relative metacognitive accuracy.

Accuracy of immediate ratings. We first focused on the comprehension rating given just after each of the paragraphs had been read. We computed, for each subject, a correlation between immediate ratings and the comprehension scores across paragraphs. The average gamma correlation was .27 . It was significantly nonzero $[t(65)=10.18, p<.001] . .^{3}$

Accuracy of delayed ratings. The relation between the delayed ratings and the comprehension performance was good (mean $G=.38$ ). The mean coefficient was positive $[t(65)=7.79, p<.001]$. The subjects appear to have been capable of predicting their comprehension performance with some accuracy.

We ran a repeated measures ANOVA contrasting the accuracy of the two rating types (immediate ratings vs. delayed ratings). This ANOVA was significant $[F(1,65)=$ $6.43, p<.05]$. Delayed ratings seem better than immediate ratings, but the lower accuracy of immediate ratings may have been due to the small number of questions used with each judgment (only two comprehension questions for each paragraph; see Weaver, 1990, for a discussion). ${ }^{4}$

These results indicate that immediate and delayed ratings have the usual validity (Maki, 1995). We will now compare the experimental effects obtained on the two types of judgments.

Rating levels. We focused on the effect of interfering task and cohesion manipulations on both rating types. We ran a $2 \times 2 \times 2$ repeated measures ANOVA contrasting the two cohesion conditions (LC vs. HC), the two interfering conditions (NIT vs. IT), and the two rating types (immediate ratings on the manipulated paragraphs vs. delayed ratings). This showed a significant interaction between the type of ratings, the interfering condition, and the cohesion manipulations $[F(1,64)=$ $4.57, p<.05]$.

The interaction between rating type, interfering condition, and cohesion was as expected. To clarify the results, we ran separate analyses for immediate and delayed ratings.

Immediate rating levels. These analyses focused on the comprehension ratings given after each of the manipulated paragraphs had been read, and Table 5 presents the mean immediate ratings as a function of cohesion, interfering condition, and paragraph type (manipulated or nonmanipulated). In order to better understand the triple interaction, we restricted our analysis to manipulated paragraphs, and we ran a $2 \times 2$ (cohesion $\times$ interfering condition) repeated measures ANOVA on the immediate ratings. This analysis showed no main effect $[F(1,64)=$ 0.26 , n.s., for cohesion and $F(1,64)=0.23$, n.s., for interfering effect] but a cohesion $\times$ interfering condition interaction $[F(1,64)=4.41, p<.05]$ for the manipulated paragraphs. Table 5 seems to show an effect of the cohesion manipulation on the immediate ratings only for the no-interfering condition. The immediate ratings were lower for the $\mathrm{LC}$ version in this condition.

This interpretation of the interaction was supported by the results of a comparison between the two cohesion conditions in a paired $t$ test for each interfering condition. We observed that only the NIT condition showed a significant effect of cohesion $[t(33)=2.826, p<.01$, for the NIT condition and $t(31)=-0.87$, n.s., for the IT condition]. For the HC paragraphs, higher ratings were observed in the NIT condition only. As predicted by our WMC model, we showed that an IT placed between the reading of a paragraph and the immediate rating regarding this paragraph wipes out the cohesion effect on the judgment.

Delayed rating levels. We will now analyze the effects on the delayed ratings. Table 6 presents the mean delayed

Table 5

Immediate Comprehension Ratings: Percentages (Experiment 2)

\begin{tabular}{|c|c|c|c|c|c|c|c|c|}
\hline & \multicolumn{4}{|c|}{ Manipulated Paragraphs } & \multicolumn{4}{|c|}{ Nonmanipulated Paragraphs } \\
\hline & \multicolumn{2}{|c|}{ High Cohesion } & \multicolumn{2}{|c|}{ Low Cohesion } & \multicolumn{2}{|c|}{ High Cohesion } & \multicolumn{2}{|c|}{ Low Cohesion } \\
\hline & $M$ & $S D$ & $M$ & $S D$ & $M$ & $S D$ & $M$ & $S D$ \\
\hline No interfering & 71.17 & 9.67 & 68.52 & 10.57 & 74.02 & 9.77 & 74.26 & 11.07 \\
\hline Interfering & 67.57 & 14.55 & 68.40 & 16.00 & 72.27 & 14.59 & 72.24 & 16.48 \\
\hline
\end{tabular}

Table 6

Mean Scores at the Delayed Comprehension Ratings and the Comprehension Questions: Percentages (Experiment 2)

\begin{tabular}{|c|c|c|c|c|c|c|c|c|}
\hline & \multicolumn{4}{|c|}{ Delayed Ratings } & \multicolumn{4}{|c|}{ Comprehension Performance } \\
\hline & \multicolumn{2}{|c|}{ High Cohesion } & \multicolumn{2}{|c|}{ Low Cohesion } & \multicolumn{2}{|c|}{ High Cohesion } & \multicolumn{2}{|c|}{ Low Cohesion } \\
\hline & $M$ & $S D$ & $M$ & $S D$ & $M$ & $S D$ & $M$ & $S D$ \\
\hline No interfering & 70.51 & 9.58 & 70.12 & 11.36 & 50.97 & 18.58 & 43.81 & 15.31 \\
\hline Interfering & 68.70 & 13.31 & 69.53 & 13.21 & 45.98 & 17.67 & 38.39 & 20.61 \\
\hline
\end{tabular}


ratings as a function of cohesion and interfering condition, as well as the mean comprehension performance. A $2 \times 2$ (cohesion $\times$ interfering condition) repeated measures ANOVA showed no main effect of cohesion or interfering manipulation on the delayed rating $[F(1,64)=0.04$, n.s., and $F(1,64)=0.19$, n.s., respectively] and no interaction between these two variables $[F(1,64)=0.33$, n.s.]. Neither the cohesion manipulation nor the interfering manipulation affected the delayed comprehension rating.

\section{Discussion}

The IT was to make the information regarding paragraph cohesion less accessible without affecting the final representation of the text. It was important that the interfering task have no effect on this representation if we were to avoid a potential confounding. The absence of an interfering effect on comprehension suggests that no indirect effect came from differences in the quality of the final representation. Because we have not observed an effect on comprehension, we conclude that the interfering manipulation did not affect (immediate or delayed) comprehension judgments through the quality of the final representation. The result in itself is not surprising. Some authors have shown that disruptions of text reading by an unrelated activity does not reliably influence the accuracy of answers to comprehension questions (Fischer \& Glanzer, 1986; Glanzer, Fischer, \& Dorfman, 1984).

Regarding the cohesion manipulation, the results were consistent with those in Experiment 1. The cohesion manipulation had an effect on comprehension performance. We observed a performance decrease for the specific comprehension questions in LC paragraphs. Yet this manipulation had no effect on the delayed comprehension judgment. This cannot be because the delayed judgment was just insensitive: Experiment 1 showed an effect of pace of reading on delayed judgment, and we observed a significant correlation between the delayed comprehension judgment and the comprehension results in both experiments.

A better explanation is provided by the WMC theory and the idea that metacognitive judgments are based on the content of WM. This hypothesis predicts that the delayed judgment is insensitive to the cohesion manipulation because the cues to the difficulties become unavailable when the reader makes the delayed judgment. The WMC theory also predicts that an interfering task between the reading of a paragraph and the immediate judgment regarding that paragraph will wipe out the cohesion effect normally observed on the immediate judgment, because the transient difficulties will have been cleared out of WM. We obtained this result. We observed a significant interaction between cohesion and interfering conditions on the manipulated paragraph judgments. The nointerfering condition showed a cohesion effect on the paragraph judgments; the interfering condition did not.

The WMC model can explain why the effect of cohesion on the immediate judgment disappears, because when an interfering task is present, the cues that remain available are the same type of cues that are available to a delayed judgment. The transitory cues are wiped out. The same pattern is expected as for a delayed judgment.

We are now in a better position to reject the amount-ofinformation explanation. Experiment 2 showed an effect of cohesion manipulations in specific circumstances on the immediate judgment that cannot be explained by the amount-of-information hypothesis, because exactly the same material was involved in both cases. If Experiment 3 can show that delayed judgments are also sensitive to cohesion manipulations, the pattern of effects will become orthogonal to the amount of information, and this interpretation will be eliminated as a credible candidate.

\section{EXPERIMENT 3}

Experiment 3 was directly inspired by Britton et al. (1991), who showed that readers can consistently compare the legibility of two versions of a text when they have access to both versions. In the experiment, we assessed the effect of the cohesion manipulation on the delayed judgment when the reader retained permanent access to the text. If we observed no cohesion effect on the delayed judgment, this would invalidate our model. If we observed this effect, it would support it: When difficulties are reinstalled in memory, LC produces lowered comprehension ratings. Making the text accessible at all points should yield a cohesion effect on the delayed judgment, because as in Britton et al. (1991), the subjects remain able to assess text quality from surface cues.

\section{Method}

Subjects. Ninety-five second-year college students first read one practice text and then the six experimental texts: Three texts were read in each of the two cohesion versions. The texts were randomly assigned to the $2 \times 2$ conditions: with or without access to the text and immediate and delayed ratings or delayed ratings only. Assignment was counterbalanced across subjects. The results of 4 subjects were not taken into account, because they turned out not to be native speakers of French.

Materials. The experimental texts were the six texts of Experiment 1. Each text had two versions: an HC version and an LC one.

Design. Two counterbalanced series of texts were constructed. Each contained the six texts: Three texts were in the HC version, and three were in the LC one. Across the two series, each text appeared once in each experimental condition. A random order of the texts was constructed. Half of the subjects saw the texts in one random order, and half saw them in the reverse order.

Procedure. The subjects were tested by groups of 12-16 in a classroom. They were asked to read a series of texts and were warned that they would be asked questions. The texts were assembled in booklets, and the subjects were asked to read texts, sentence by sentence, at their own pace. We asked them not to go back during reading, in order to minimize differences with the reading conditions in Experiments 1 and 2. The subjects gave their comprehension ratings on a $0-20$ scale, a scale used for class grades at the university. Half of the subjects were encouraged to return to the text and read again some parts of the text when making their judgment, "in order to improve the judgment" (access to the text, AT). The other half were not allowed to return to the text when making their judgment (no access to the text, NAT). Moreover, half of the subjects in each access condition gave both an immediate rating after reading each paragraph and a delayed rating after each text (both 
ratings), whereas the other half gave only a delayed rating after reading each text. This number-of-ratings factor was introduced because returning to the text to make the immediate rating in the AT condition could have an effect on the delayed ratings. Since the reader was encouraged to reread each paragraph before reading the next one, the reader might integrate new information better in the AT condition, whatever the cohesion. Using a condition in which the readers provide only delayed ratings would allow detection of such an effect if it did occur. In this delayed ratings condition, the subjects were asked to count backward by three for $10 \mathrm{sec}$ before making their ratings, in order to introduce the same lapse of time between the end of reading and the delayed rating than in the both ratings condition.

In Experiment 3, the readers only assessed their comprehension. Although they were led to believe that they would have a comprehension test, no comprehension question was eventually asked. The dependent variables were just the comprehension ratings (immediate and delayed). The whole experiment took about $40 \mathrm{~min}$.

Pretest. Twenty-four speakers of French participated in a pretest. The pretest showed that a question should be added at the end of the experiment to make sure that the subjects in the AT condition actually returned to the text before making their judgments. The question was Pour donner vos jugements sur les paragraphes (les textes), êtes-vous revenus aux paragraphes (aux textes) et en avez-vous relu certaines parties? Toujours-Presque toujours-Souvent-ParfoisJamais/To make your judgment on the paragraphs (texts), did you return to the paragraphs (texts) and did you read again some parts? Always-Almost Always-Often-Sometimes-Never.

\section{Results}

No performance test was used in this experiment, so that we have no comprehension score and no accuracy measure. We will analyze only rating levels.

Rating levels. We ran a $2 \times 2 \times 2$ repeated measures ANOVA on both rating types, contrasting the two access conditions (AT vs. NAT), the two cohesion conditions (LC vs. HC), and the two rating types (immediate ratings on the manipulated paragraphs vs. delayed ratings in the delayed ratings condition). An effect of cohesion $[F(1,87)=37.62, p<.001]$ and an effect of rating type $[F(1,87)=4.13, p<.05]$ were found, but we also ob- served a significant interaction between access condition and cohesion $[F(1,87)=7.19, p<.01]$ and a significant interaction between access condition, rating type, and cohesion $[F(1,87)=4.88, p<.05]$.

To clarify the results, we ran separate analyses for immediate and delayed ratings.

Immediate rating levels. These analyses focused on the comprehension rating given after each of the manipulated paragraphs had been read. Table 7 presents the mean immediate ratings as a function of cohesion and access to the text. We ran a $2 \times 2$ (cohesion $\times$ access condition) repeated measures ANOVA on the immediate ratings. This analysis showed a main effect of cohesion $[F(1,45)=27.07, p<.001]$, no effect of access condition $[F(1,45)=0.02$, n.s.], and no cohesion $\times$ access interaction $[F(1,45)=0.11$, n.s.]. Table 7 shows that the immediate ratings were lower for the $\mathrm{LC}$ version than for the $\mathrm{HC}$ version in the two access conditions. So, as predicted by our $W M C$ model, we showed a cohesion effect on immediate ratings when there was no interfering task between the reading of a paragraph and the immediate rating regarding this paragraph. This effect was observed whether the reader was allowed to return to the paragraph before making the judgment or not.

Delayed rating levels. We will now analyze the effects on the delayed ratings. Table 8 presents the mean delayed ratings as a function of cohesion and access to the text, separately according to the number-of-ratings condition (delayed ratings vs. both ratings). A $2 \times 2 \times 2$ (cohesion $\times$ access $\times$ number of ratings condition) repeated measures ANOVA showed a main effect of cohesion $[F(1,87)=4.81, p<.05]$, a main effect of the number of ratings $[F(1,87)=8.69, p<.01]$, but also an interaction between the cohesion and the access conditions $[F(1,87)=8.19, p<.01]$ and an interaction between the cohesion and the number of ratings $[F(1,87)=$ $5.31, p<.05]$. Table 8 seems to show an effect of the co-

Table 7

Immediate Comprehension Ratings: Percentages (Experiment 3)

\begin{tabular}{|c|c|c|c|c|c|c|c|c|}
\hline & \multicolumn{4}{|c|}{ Manipulated Paragraphs } & \multicolumn{4}{|c|}{ Nonmanipulated Paragraphs } \\
\hline & \multicolumn{2}{|c|}{ High Cohesion } & \multicolumn{2}{|c|}{ Low Cohesion } & \multicolumn{2}{|c|}{ High Cohesion } & \multicolumn{2}{|c|}{ Low Cohesion } \\
\hline & $M$ & $S D$ & $M$ & $S D$ & $M$ & $S D$ & $M$ & $S D$ \\
\hline No text access & 80.80 & 8.35 & 75.29 & 10.40 & 79.42 & 11.54 & 82.97 & 10.02 \\
\hline Text access & 81.67 & 13.49 & 75.41 & 16.16 & 83.26 & 12.87 & 84.51 & 11.88 \\
\hline
\end{tabular}

Table 8

Mean Scores at the Delayed Comprehension Ratings: Percentages (Experiment 3)

\begin{tabular}{|c|c|c|c|c|c|c|c|c|}
\hline & \multicolumn{4}{|c|}{ Delayed Ratings in DR Condition } & \multicolumn{4}{|c|}{ Delayed Ratings in BR Condition } \\
\hline & \multicolumn{2}{|c|}{ High Cohesion } & \multicolumn{2}{|c|}{ Low Cohesion } & \multicolumn{2}{|c|}{ High Cohesion } & \multicolumn{2}{|c|}{ Low Cohesion } \\
\hline & $M$ & $S D$ & $M$ & $S D$ & $M$ & $S D$ & $M$ & $S D$ \\
\hline No text access & 71.97 & 9.49 & 71.97 & 9.63 & 78.18 & 9.37 & 79.35 & 10.08 \\
\hline Text access & 79.31 & 9.82 & 71.51 & 11.60 & 81.39 & 12.32 & 80.42 & 12.85 \\
\hline
\end{tabular}

Note-DR, delayed ratings; BR, both ratings. 
hesion manipulation on the delayed ratings only for the AT condition in the delayed ratings condition. The ratings were lower for the $\mathrm{LC}$ version in this condition.

Again, we ran separate analyses as a function of the number-of-ratings condition (delayed ratings vs. both ratings).

We first computed a $2 \times 2$ (cohesion $\times$ access) repeated measures ANOVA on the ratings in the delayed ratings condition. We observed a main effect of cohesion $[F(1,42)=12.09, p<.01]$ and a cohesion $\times$ access interaction $[F(1,42)=12.07, p<.01]$. The cohesion manipulation seems to have affected the delayed ratings only when the subjects were allowed to go back to the text before giving their ratings (see Table 8). This interpretation of the significant interaction was supported by the results of a comparison between the two cohesion conditions in a paired $t$ test for each access condition. We observed that only the AT condition showed a significant effect of cohesion $[t(21)=4.12, p<.001$, for the AT condition and $t(21)<0.01$, n.s., for the NAT condition]. Higher ratings were observed for the HC paragraphs in the AT condition only. As predicted by our WMC model, these results seem to show that reinstating difficulties in $\mathrm{WM}$ at the time the delayed judgment is made makes the judgment sensitive to these difficulties.

Second, we computed the same $2 \times 2$ (cohesion $\times$ access) repeated measures ANOVA on the delayed ratings in the both ratings condition. In this condition, we observed neither a cohesion effect $[F(1,45)=0.01$, n.s.], nor a cohesion $\times$ access interaction $[F(1,45)=0.66$, n.s.]. The cohesion manipulation did not affect the delayed ratings when the subjects gave the judgments after each paragraph. This effect is absent from both access conditions (see Table 8).

To summarize, the results are completely different in the both ratings and the delayed ratings conditions. We considered two explanations for this. First, a possibility mentioned above, the subjects may have constructed a better representation in the both ratings condition because they read each paragraph twice (Millis, Simon, \& tenBroek, 1998). Reading a paragraph a second time before they moved to the next may have smoothed out a number of the difficulties in the LC version. In this case, delayed ratings should be higher globally when each paragraph is read twice (Rawson et al., 2000). This is the trend observed in Table 8.
A second possible reason why there was no interaction between cohesion and accessed when the readers assessed each paragraph may be that the readers did not follow the instructions as closely in this condition. After returning a first time to the text when making a judgment on each paragraph, the readers may not have thought it necessary to return again to the text when making the delayed judgment. This would make the access manipulation less effective. The question we asked regarding the actual return to the text when the delayed judgment was made provides some information on this. The results in Table 9 actually seem to show that the readers returned to the text less often when they had already returned to the text after each paragraph for the immediate judgment (in the both ratings condition). In order to test this effect, we used extensions of the Mantel-Haenszel statistics (van Elteren, 1960; see Lehmann, 1975) designed to investigate a response variable containing multiple ordered outcomes (Stokes, Davis, \& Koch, 2000, p. 67). The statistic computed tested a difference in the actual return ordinal variable across levels of the number-of-ratings factor, using only the delayed rating data. It was clearly significant $\left[Q_{s}(1)=15.31, p<.0001\right]$, indicating a lower proportion of text return for the delayed judgment when readers already had returned to the text after each paragraph.

In order to gather more support for this interpretation, we also computed the correlation between the frequency of returns to the text for each subject and a measure of the cohesion effect. This measure was the difference between the means of the delayed judgments for the $\mathrm{HC}$ versions and for the LC versions, for each subject. The gamma correlation was .51 and was significantly nonzero $[t(46)=4.58, p<.001]$. The more a subject returned to the text to read again some parts, the larger the effect of cohesion on the delayed ratings. To summarize, the analyses show that the delayed rating is affected by text cohesion when readers do return to a text to make their judgments. This effect does not occur when readers assess comprehension after each paragraph. Two distinct but compatible explanations have been proposed for this. First, comprehension might be equivalent between the two versions because the paragraph judgments and the second reading (made before moving to the next paragraph) may have solved difficulties in the LC versions. Second, difficulties may not be reinstated in WM when

Table 9

Frequencies of the Various Answers to the Question of "Actual Return" to the Text in the Access Condition (Experiment 3)

\begin{tabular}{lcccc}
\hline & DR Condition & & \multicolumn{2}{c}{ BR Condition } \\
\cline { 2 - 2 } \cline { 5 - 6 } \cline { 5 - 6 } & Delayed Ratings & & Delayed Ratings & Immediate Ratings \\
\hline Jamais/never & 5 & & 17 & 3 \\
Parfois/sometimes & 6 & & 0 & 11 \\
Souvent/often & 5 & & 0 & 9 \\
Presque toujours/almost always & 6 & & 0 & 1 \\
Toujours/always & 0 & & 0
\end{tabular}

Note-DR, delayed ratings; BR, both ratings. 
readers do not return to a text at the moment at which a delayed judgment is made. This happens more often if the same readers have already read the text several times in order to make paragraph judgments.

\section{Discussion}

Our WMC model postulates a difference in cue utilization between immediate and delayed judgments. The difference regards temporary cues that affect only immediate judgments. The results confirm what was observed in Experiments 1 and 2 for immediate judgments. The transient cues related to cohesion affect the immediate judgment because difficulties are still in WM when the reader makes this judgment.

The effect of the number of judgments on delayed judgment is a source of questions. We observe a higher delayed judgment when it is preceded by immediate judgments. Simply assessing comprehension after each paragraph may have affected delayed judgment. The most interesting explanation would be that a richer representation is constructed when judgments are made during reading. Paragraph assessment may produce what Butler and Winne (1995) call internal feedback (a comparison of evolving states of a task to goals). Assessing comprehension may provide for a regulation and an adaptation in the reading of subsequent paragraphs. Making a judgment after a paragraph may also force the reader to retrieve information relevant to that paragraph and may improve integration with the subsequent ones, as well as comprehension in general (Spellman \& Bjork, 1992). Although these are interesting hypotheses, we cannot test them, because no comprehension measure was included. The point of Experiment 3 was only to study the metacognitive ratings.

The analysis of delayed judgments also shows an interaction between number of judgments and cohesion: There is a cohesion effect after a single delayed judgment (delayed ratings condition), but not after multiple judgments (both ratings condition). This might result from a richer representation in the both ratings condition, but also from a failure to return again to the text by readers who have already had to return to this text for immediate judgments.

\section{CONCLUSION}

Current theories of metacognition (e.g., Koriat, 1997) suggest that inferential processes rely on different cues according to circumstances. With regard to text comprehension and metacomprehension, we must be able to explain how and why these cues change. Our WMC hypothesis states that the judgment varies according to the content of WM at the moment the judgment is made.

We tested predictions of this hypothesis in three experiments in which the effect of text cohesion on both immediate and delayed comprehension judgments was examined. We showed that cohesion difficulties can affect judgments only as long as information relative to them remains directly available, presumably in WM, and usually not when the judgment is delayed. Experiment 1 showed a cohesion effect on immediate judgments, but not on delayed judgments. Experiment 2 showed that the cohesion effect on the immediate judgment disappears if a 30- to 60-sec interfering task is introduced between the reading of the paragraph and the making of the judgment. So the cohesion manipulation affects the immediate judgment only as long as WM traces remain available. Experiment 3 adopted a reversed approach and showed that the delayed judgment can be influenced by transient cues, provided that these cues are reinstated at the time the judgment is made. This, in our view, is the most likely explanation of the results. Yet we cannot be completely sure that the reader does not introduce some new cue during rereading. Such a cue may result, for instance, from a comparison between the various texts. In any case, the results prove that the cues are different at this moment, which is the critical point. At the same time, we showed in Experiment 1 that cues that are less transient (related to time constraints, for instance) produce an effect on both types of judgments.

Although the results match the predictions of the WMC hypothesis, they do not fit as well with a number of alternative explanations.

First, the single pace-of-reading effect on delayed judgment without any cohesion effect does not fit well with Koriat's (1997) formulation of the cue utilization hypothesis. Koriat's results on the JOL suggest a greater sensitivity of the ratings to intrinsic factors that we did not observe (cohesion is an intrinsic factor in Koriat's sense, and pace of reading is an extrinsic one). In any case, his formulation does not seem to apply as such to text comprehension and memorization. Our conclusion is in accord with the results of Carroll and Korukina (1999), who observed an effect of modality of presentation of a discourse (an extrinsic factor) on the JOL given in a situation of text comprehension and memorization. Our WMC hypothesis, therefore, appears to represent an interesting instantiation of the cue utilization approach for the particular situation of text comprehension. It rests on the specific role of WM in reading and on the dynamics of loading and unloading specific cues from WM. This integrates well with current theories of comprehension (e.g., van den Broek, Young, Tzeng, \& Linderholm, 1999).

The results do not fit well either with an explanation that might be invoked on the basis of a technical difficulty. The difficulty is that in our three experiments, only one half of the paragraphs were actually submitted to the cohesion manipulation (one paragraph out of two). This suggests a dilution explanation of the results obtained on delayed judgments. According to the dilution explanation, the delayed judgment could be a simple average of the immediate judgments. The subjects would average their immediate judgments to make up a delayed judgment. These judgments would be based on both manipulated and nonmanipulated paragraphs, and this would lead to some form of attenuation of the apparent effect of cohesion. This is especially a problem in Experiment 1, where it could explain the results - in particular, the 
asymmetry of effects between the two types of judgments. Yet the explanation does not seem convincing, given the results of Experiments 2 and 3. It does not explain why the cohesion effect on immediate judgments would disappear when an interfering task is introduced (Experiment 2). It cannot explain either why the cohesion effect is obtained on delayed judgment if the readers are allowed to return to the text when giving their rating (Experiment 3). Again, the WMC hypothesis seems to explain the results more economically.

A third hypothesis that must be eliminated involves the amount of information processed (Commander \& Stanwyck, 1997). The quality of the ratings may differ according to the amount of text (information) on which the judgment is based. The effects would, therefore, disappear with longer text segments. Yet in Experiments 2 and 3, cohesion effects appear and disappear both on immediate and delayed judgments and independently of the length of the text involved. This seems to rule out such an interpretation.

The results obtained do not seem to fit either with the predictions of a general adaptation hypothesis (Moore et al., 1997). Such a conception would suggest that factors affecting comprehension should equally influence judgments. We observed several dissociations of the effects on cognition and metacognition in our results.

Finally, the low sensitivity of the delayed judgment to cohesion manipulations observed in this research apparently is not in accord with recent results by Rawson and Dunlosky (2002). Rawson and Dunlosky manipulated ease of inference, ease of integrating propositions, and ease of access to the lexicon, and they always observed an effect of ease of processing on the metacognitive judgment. Yet the results are complex. The experiments in which pairs of sentences (Experiments 1 and 2) or paragraphs (Experiment 4) were used yielded results that are compatible with our own. They involved a judgment that we might call immediate because the text was very short. The results of their Experiment 3, based on Britton and Gülgöz's (1991) revision technique, do seem difficult to understand in the WMC model. The experiment showed an effect of the cohesion manipulation on what we would call delayed judgments (given after complete reading of the text), but there may be several explanations. Rawson and Dunlosky used performance prediction as a dependent variable, whereas we used a judgment of comprehension. The two judgments may differ. Rawson, Dunlosky, and McDonald (2002) have shown that performance prediction weights retention of information more heavily. Maki et al. (1990) also showed that performance prediction and the ease of comprehension judgments are not equivalent. These results might be taken to suggest that a performance prediction made after reading a text would be sensitive to cohesion manipulation, whereas a judgment of comprehension would not be. However, this is not conclusive, because Degand et al. (1999) observed no cohesion effect on a performance prediction given after reading each text. Another, possibly more convincing explanation might be that Rawson and Dunlosky's subjects always gave a performance prediction immediately after reading a text the last propositions of which were manipulated. Some cues to the difficulty of treatment might still have been available in WM when such a judgment was made.

Other studies have dealt with ease of comprehension as a factor of accuracy and have focused on the quality of the judgments as predictors of performance (Maki \& Serra, 1992; Rawson et al., 2000). We did not address this question. Our WMC model predicts only effects on the magnitude of the comprehension judgment. Other factors should be included in order to make predictions with regard to accuracy. Specifically, we should be able to make concrete assessments of the validity of the various cues actually used by the readers before we can predict whether accuracy will increase or decrease according to conditions. Moreover, the assessment of predictive accuracy may be affected by a number of extraneous and irrelevant factors, as was suggested by Rawson and Dunlosky (2002, p. 70). The fact that the model requires auxiliary hypotheses to deal with accuracy is well illustrated by the results of Maki (1998a) regarding the effect of a delay between reading, judgment, and test. The results show that accuracy decreases when performance prediction and test are not given in close succession. The best accuracy is obtained for an immediate judgment and an immediate test.

The effects we have presented and discussed are simpler. They have been obtained on the level of the rating, not on accuracy. So there is no contradiction between results. On the other hand, the model can explain effects such as Maki's (1998a), using auxiliary hypotheses, but actually it makes no general prediction. One should probably predict that the cues present in WM and used for prediction will be more dissimilar if more time elapses. Therefore, we can safely assume that immediate and delayed judgments are not based on the same cues, but detailed predictions regarding accuracy depend on what these cues happen to be good for.

Generally speaking, the WMC hypothesis is in agreement with metacognitive theories that stress the role of WM contents (Koriat, 1993, 1995; Nelson \& Narens, 1990) and with the idea that multiple types of cues are used for metacognitive judgments (Koriat, 1997; Maki, $1998 \mathrm{~b}$ ). The fact that the information available may vary from one moment - or from one task - to the next sheds some light on the results that show an instability of metacognitive accuracy across circumstances or tasks.

\section{REFERENCES}

Breznitz, Z., \& Share, D. L. (1992). Effects of accelerated reading rate on memory for text. Journal of Educational Psychology, 84, 193199.

BRITTON, B. K., \& GÜLGÖz, S. (1991). Using Kintsch's computational model to improve instructional text: Effects of repairing inference calls on recall and cognitive structures. Journal of Educational Psychology, 83, 329-345.

Britton, B. K., GÜlgöz, S., VAn Dusen, L., GlynN, S. M., \& Sharp, L. 
(1991). Accuracy of learnability judgments for instructional texts. Journal of Educational Psychology, 83, 43-47.

BRITTON, B. K., \& RADFORD, D. (1988). Improving biology texts by rewriting. Unpublished manuscript.

Britton, B. K., VAN Dusen, L., GülgÖz, S., \& GlynN, S. M. (1989). Instructional texts rewritten by five expert teams: Revisions and retention improvements. Journal of Educational Psychology, 81, 226-239.

Butler, D. L., \& WinNe, P. H. (1995). Feedback and self-regulated learning: A theoretical synthesis. Review of Educational Research, 65, 245-281.

CARROLL, M., \& Korukina, S. (1999). The effect of text coherence and modality on metamemory judgments. Memory, 7, 309-322.

Carroll, M., \& Nelson, T. O. (1993). Effects of overlearning on the feeling of knowing are more detectable in within-subject than in betweensubject designs. American Journal of Psychology, 106, 227-235.

Commander, N. E., \& STANWyck, D. J. (1997). Illusion of knowing in adult readers: Effects of reading skill and passage length. Contemporary Educational Psychology, 22, 39-52.

Cross, D. R., \& PARIS, S. G. (1988). Developmental and instructional analyses of children's metacognition and reading comprehension. Journal of Educational Psychology, 80, 131-142.

Degand, L., LefÈvre, N., \& Bestgen, Y. (1999). The impact of connectives and anaphoric expressions on expository discourse comprehension. Document Design, 1, 39-51.

Dunlosky, J., \& Nelson, T. O. (1992). Importance of the kind of cue for judgments of learning (JOL) and the delayed-JOL effect. Memory \& Cognition, 20, 374-380.

Dunlosky, J., \& Nelson, T. O. (1994). Does the sensitivity of judgments of learning (JOLs) to the effects of various study activities depend on when the JOLs occur? Journal of Memory \& Language, 33 , 545-565.

DUNlosky, J., \& Nelson, T. O. (1997). Similarity between the cue for judgments of learning (JOL) and the cue for test is not the primary determinant of JOL accuracy. Journal of Memory \& Language, $\mathbf{3 6}_{2}$ 34-49.

EHRLICH, M. F., \& CAHOUR, B. (1991). Contrôle métacognitif de la compréhension: Cohésion d'un texte expositif et auto-évaluation de la compréhension. Bulletin de Psychologie, 44, 147-155.

Fischer, B., \& Glanzer, M. (1986). Short-term memory function in young readers. Journal of Experimental Child Psychology, 19, 279298.

Gaonac'H, D., \& Passerault, J. M. (1990). A.D.F.M.: A technic for the study of reading activities. Golem, 1, 11.

GARNER, R. (1987). Metacognition and reading comprehension. Norwood, NJ: Ablex.

Glanzer, M., Fischer, B., \& Dorfman, D. (1984). Short-term storage in reading. Journal of Verbal Learning \& Verbal Behavior, 23, 467-486.

HACKER, D. J. (1998). Definitions and empirical foundation. In D. J. Hacker, J. Dunlosky, \& A. C. Graesser (Eds.), Metacognition in educational theory and practice (pp. 1-23). Mahwah, NJ: Erlbaum.

Hacker, D. J., Dunlosky, J., \& Graesser, A. C. (1998). Metacognition in educational theory and practice. Mahwah, NJ: Erlbaum.

Hertzog, C., Dixon, R. A., \& Hultsch, D. F. (1990). Relationships between metamemory, memory predictions, and memory task performance in adults. Psychology \& Aging, 5, 215-227.

Just, M. A., Carpenter, P. A., \& Wooley, J. D. (1982). Paradigms and processes in reading comprehension. Journal of Experimental Psychology: General, 3, 228-238.

Kelemen, W. L., \& Weaver, C. A., III (1997). Enhanced metamemory at delays: Why do judgments of learning improve over time? Journal of Experimental Psychology: Learning, Memory, \& Cognition, 23, 1394-1409.

KING, A. (1991). Improving lecture comprehension: Effects of a metacognitive strategy. Applied Cognitive Psychology, 5, 331-346.

King, J. F., Zechmeister, E. B., \& Shaughnessy, J. J. (1980). Judgments of knowing: The influence of retrieval practice. American Journal of Psychology, 93, 329-343.

Koriat, A. (1993). How do we know what we know? The accessibility account of the feeling of knowing. Psychological Review, 100, 609-639.

KorIAT, A. (1995). Dissociating knowing and the feeling of knowing:
Further evidence for the accessibility model. Journal of Experimental Psychology: General, 124, 311-333.

KORIAT, A. (1997). Monitoring one's own knowledge during study: A cue-utilization approach to judgments of learning. Journal of Experimental Psychology: General, 126, 349-370.

LEFÈVRE, N. (2003). Compréhension et métacompréhension: De la non-concordance à la variabilité des indices. Doctoral dissertation, Université catholique de Louvain, Louvain-la-Neuve.

Lehmann, E. L. (1975). Nonparametrics: Statistical methods based on ranks. San Francisco: Holden-Day.

Lin, L. M., Zabrucky, K. M., \& Moore, D. (2002). Effects of text difficulty and adults' age on relative calibration of comprehension. American Journal of Psychology, 115, 187-198.

MAKI, R. H. (1995). Accuracy of metacomprehension judgments for questions of varying importance levels. American Journal of Psychology, 108, 327-344.

MAKI, R. H. (1998a). Predicting performance on text: Delayed versus immediate predictions and tests. Memory \& Cognition, 26, 959-964.

MAKI, R. H. (1998b). Test predictions over text material. In D. J. Hacker, J. Dunlosky, \& A. C. Graesser (Eds.), Metacognition in educational theory and practice (pp. 117-144). Mahwah, NJ: Erlbaum.

Maki, R. H., Foley, J. M., KaJer, W. K., Thompson, R. C., \& WILLERT, M. G. (1990). Increased processing enhances calibration of comprehension. Journal of Experimental Psychology: Learning, Memory, \& Cognition, 16, 609-616.

MAKI, R. H., \& SERRA, M. (1992). The basis of test predictions for text material. Journal of Experimental Psychology: Learning, Memory, \& Cognition, 18, 116-126.

Millis, K. K., SimON, S., \& TEnBroeK, N. S. (1998). Resource allocation during the rereading of scientific texts. Memory \& Cognition, 26, 232-246.

Móre, D., Zabrucky, K., \& Commander, N. E. (1997). Metacomprehension and comprehension performance in younger and older adults. Educational Gerontology, 23, 467-475.

Morris, C. C. (1990). Retrieval processes underlying confidence in comprehension judgments. Journal of Experimental Psychology: Learning, Memory, \& Cognition, 16, 223-232.

Nelson, T. O. (1984). A comparison of current measures of the accuracy of feeling-of-knowing predictions. Psychological Bulletin, $\mathbf{9 5}$, 109-133.

NELSON, T. O. (1996). Gamma is a measure of the accuracy of predicting performance on one item relative to another item, not of the absolute performance on an individual item. Applied Cognitive Psychology, 10, 257-260.

NELSON, T. O., \& DunLosky, J. (1991). When people's judgments of learning (JOLs) are extremely accurate at predicting subsequent recall: The "delayed-JOL effect." Psychological Science, 2, 267-270.

Nelson, T. O., \& NARENS, L. (1990). Metamemory: A theoretical framework and new findings. In G. Bower (Ed.), The psychology of learning and motivation (Vol. 26, pp. 125-141). San Diego: Academic Press.

Otero, J., \& KintsCh, W. (1992). Failure to detect contradictions in a text: What readers believe versus what they read. Psychological Science, 3, 229-235.

PALINCSAR, A. S., \& Brown, A. L. (1984). Reciprocal teaching of comprehension-fostering and comprehension-monitoring activities. Cognition \& Instruction, 1, 117-175.

PARIS, S. G., \& WINOGRAD, P. (1990). How metacognition can promote academic learning and instruction. In B. F. Jones \& L. Idol (Eds.), Dimensions of thinking and cognitive instruction (pp. 15-51). Hillsdale, NJ: Erlbaum.

Passerault, J. M., \& GaOnac'H, D. (1991). Delayed process monitoring during reading in slow and fast readers. Cahiers de Psychologie Cognitive/European Bulletin of Cognitive Psychology, 11, 371-383.

Pierce, B. H., \& Smith, S. M. (2001). The postdiction superiority effect in metacomprehension of text. Memory \& Cognition, 29, 62-67.

Pratt, M. W., Luszcz, M. A., MacKenZie-Keating, S., \& ManNing, A. (1982). Thinking about stories: The story schema in metacognition. Journal of Verbal Learning \& Verbal Behavior, 21, 493-505.

RaWson, K. A., \& DUnlosky, J. (2002). Are performance predictions 
for text based on ease of processing? Journal of Experimental Psychology: Learning, Memory, \& Cognition, 28, 69-80.

RaWson, K. A., Dunlosky, J., \& McDonald, S. L. (2002). Influences of metamemory on performance predictions for text. Quarterly Journal of Experimental Psychology, 55, 505-524.

Rawson, K. A., Dunlosky, J., \& Thiede, K. W. (2000). The rereading effect: Metacomprehension accuracy improves across reading trials. Memory \& Cognition, 28, 1004-1010.

SHAUGHNESSY, J. J. (1979). Confidence-judgment accuracy as a predictor of test performance. Journal of Research in Personality, 13, 505-514.

Spellman, B. A., \& BJork, R. A. (1992). When predictions create reality: Judgments of learning may alter what they are intended to assess. Psychological Science, 3, 315-316.

Stokes, M. E., Davis, C. S., \& Koch, G. G. (2000). Categorical data analysis using the $S A S \circledR$ system. Cary, NC: SAS Institute.

van den Broek, P., Risden, K., \& Husebye-Hartmann, E. (1995). The role of readers' standards for coherence in the generation of inferences during reading. In R. F. Lorch \& E. J. O'Brien (Eds.), Sources of coherence in reading (pp. 353-374). London: Academic Press.

van den Broek, P., Young, M., Tzeng, Y., \& Linderholm, T. (1999). The landscape model of reading: Inferences and the online construction of a memory representation. In H. van Oostendorp \& S. R. Goldman (Eds.), The construction of mental representations during reading (pp. 71-97). Mahwah, NJ: Erlbaum.

VAN DE VELDE, R. G. (1989). Man, verbal text, inferencing, and coherence. In W. Heydrich, F. Neubauer, J. S. Petofi, \& E. Sozer (Eds.), Connexity and coherence: Analysis of text and discourse (pp. 174217). New York: de Gruyter.
VAN Elteren, P. H. (1960). On the combination of independent twosample tests of Wilcoxon. Bulletin of the International Statistical Institute, 37, 351-361.

Wearn, Y., \& AsKWall, S. (1981). On some sources of metacomprehension. Scandinavian Journal of Psychology, 22, 17-25.

WeAVER, C. A., III (1990). Constraining factors in calibration of comprehension. Journal of Experimental Psychology: Learning, Memory, \& Cognition, 16, 214-222.

Weaver, C. A., III, \& Kelemen, W. L. (1997). Judgments of learning at delays: Shifts in response patterns or increased metamemory accuracy? Psychological Science, 8, 318-321.

WrAY, D. (1994). Comprehension monitoring, metacognition and other mysterious processes. Support for Learning, 9, 107-113.

Zechmeister, E. B., Rusch, K. M., \& Markell, K. A. (1986). Training college students to assess accurately what they know and don't know. Human Learning, 5, 3-19.

\section{NOTES}

1. Computing the average ratings across the four paragraphs and correlating these with performance on each text yields an average gamma of .44 , significantly nonzero $[t(54)=10.81, p<.001]$.

2. Using average ratings, we no longer find an accuracy difference between types of judgments $[F(1,53)=0.18$, n.s. $]$.

3 . Using average ratings yields a mean gamma correlation of .29 , significantly nonzero $[t(64)=7.18, p<.001]$.

4. Using average ratings, we no longer find an accuracy difference between the two judgments $[F(1,64)=2.90$, n.s. $]$.

\section{APPENDIX}

\section{Example of Text Used in the Three Experiments: "The Aztecs"}

\section{High-Cohesion Version}

Paragraph 1: Nonmanipulated. The Aztecs dominated central and southern Mexico from the 14th to the 16 th century. What we know of their history started with the arrival of immigrants on the central mexican plateau. Being the last arrived in the Mexico City valley, the Aztecs were forced to settle in the swampy area around Tex Coco lake. They were circled and ransomed by powerful neighbors and their only piece of dry land was a small island in the middle of the swamps. From these modest beginnings, they were raised, over the next 2 centuries, to a powerful empire because of one legend they entertained. According to the legend, they were to create a great civilization in the swamps where they would see a cactus grown on a rock with, at the top, an eagle devouring a snake. The priests said that they had seen this when they arrived in the swamps.

Paragraph 1 Rating

Paragraph 2: Manipulated. As the number of Aztecs grew, they established civil and military structures. The Aztecs changed the bed of the lake into fertile gardens by piling up mud on the bottom of the lake. They built roads and bridges to link the city to the shore. Canals were dug through the city for the transportation of people and merchandise. The Aztecs made military alliances with the cities that were close to their own. Progressively, they created an empire that extended from the center of Mexico to the present border of Guatemala. Yet some populations on the borders of the Aztec empire remained fiercely independent. Internal divisions and dissent facilitated the Spanish victory against the Aztecs in 1521.

\section{Paragraph 2 Rating}

Paragraph 3: Manipulated. In the Aztec religion, numerous gods governed day-to-day life. You could find among these gods, the Moon goddess, the Sun god, the Rain god and the inventor of writing and the calendar. Animal and human sacrifices were an integral part of the Aztec religion. For a warrior, the supreme honor was to get killed in a great ceremony during the sacrifices or to die fighting. Nevertheless, prisoners were often used for the sacrifices, especially when the ceremony was minor. The victims climbed the steps of the pyramid, where the priests had them lie on a convex stone. Next, the priests extracted the victims' heart with a sharp knife.

\section{Paragraph 3 Rating}

Paragraph 4: Nonmanipulated. The Aztecs used an ideographic system to write on animal skins. Some of these manuscripts survive today. They also had a calendar system, developed by the Mayan people. The system involved 365 days, distributed on 18 months of 20 days, to which 5 "empty" days were added that were considered inauspicious. The Aztec society was divided into three classes: slaves, commoners, and the aris- 
tocracy. Today, the Aztecs live in the Mexico City area and make up a population of about one million. They are the largest indigenous group in Mexico. They have preserved their language and their religion is a mixture of the Aztec tradition and Catholicism.

\section{Paragraph 4 Rating}

\section{Final Rating}

\section{Low-Cohesion Version}

...

Paragraph 2: Manipulated. As their number grew, they established civil and military structures. They changed the bed of the lake into fertile gardens by piling up mud on its bottom. They built roads and bridges to link the city to the shore. Canals were dug through it for the transportation of people and merchandise. They made military alliances with those who were close to their own. Progressively, they created an empire that stretched from the center of Mexico to the present border of Guatemala. Yet some populations on the borders of $i t$ remained fiercely independent. Internal divisions and dissent facilitated the Spanish victory against them in 1521.

Paragraph 2 Rating

Paragraph 3: Manipulated. In their religion, numerous gods governed day-to-day life. You could find among them, the Moon *, the Sun *, the Rain, and the inventor of writing and the calendar. Animal and human sacrifices were an integral part of the Aztec religion. For a warrior, the supreme honor was to get killed in a great ceremony during the sacrifices or to die fighting. Nevertheless, prisoners were often used for these, especially when it was minor. The victims climbed the steps of the pyramid, where the priests had them lie on a convex stone. Next, they extracted their heart with a sharp knife.

Paragraph 3 Rating

...

(The nominal entities manipulated are in italic.)

\section{Example of Questions From Text: "The Aztecs"}

1. What does the Aztec legend say?

2. What is the supreme honor for an Aztec warrior?

3. How many Aztecs are left today?

4. With whom did the Aztecs conclude military alliances?

5. What can be said of the Aztec manuscripts that survive today?

6. Where were the Aztecs forced to settle when they arrived in the Mexico City valley?

7. What was the size of the Aztec empire at its largest?

8. In what circumstances were prisoners used for sacrifices?

Table A1 lists the eight questions with the type of the paragraph concerned and the question type.

Table A1

Characteristics of the Example Questions (Experiments 1 and 2)

\begin{tabular}{ccccc}
\hline \multicolumn{3}{c}{ Number of } & & \multicolumn{2}{c}{ Type of } \\
\cline { 2 - 3 } Question & Paragraph & & Paragraph & Question \\
\hline 1 & 3 & nonmanipulated & integration \\
2 & 4 & manipulated & detail \\
3 & 2 & nonmanipulated & integration \\
4 & 4 & manipulated & integration \\
5 & 1 & nonmanipulated & detail \\
6 & 2 & nonmanipulated & detail \\
7 & 3 & manipulated & integration \\
8 & & manipulated &
\end{tabular}

(Manuscript received April 12, 2002;

revision accepted for publication April 5, 2004.) 